Horizons in Textual Criticism 


\title{
Horizons in Textual Criticism: New Approaches and New Questions
}

\author{
John Screnock and Jan Joosten ${ }^{*}$ \\ University of Oxford, Oxford, United Kingdom \\ john.screnock@orinst.ox.ac.uk jan.joosten@orinst.ox.ac.uk
}

On 10-11 May, 2017, we convened a colloquium, "Horizons in Textual Criticism," at the University of Oxford. The colloquium brought together an international cohort of text-critics, in conversation on new methodologies and perspectives in textual criticism of the Hebrew Bible and related texts. Focusing on engagement and discussion, the colloquium maximized opportunity for feedback, including key input from senior scholars in the field: Ron Hendel, Jan Joosten, Michael Segal, Alison Salvesen, and Hugh Williamson. Five of the papers from that colloquium are presented in this section of Textus. ${ }^{1}$

The discovery of the Dead Sea scrolls produced seismic shifts in the textual criticism of the Hebrew Bible. Now, after their full publication, scholars continue to question old assumptions and rethink the methodologies we apply to text-critical evidence. The five articles presented here respond in one way or another to the Scrolls, and are representative of the methodological recalibrating necessitated by the Scrolls. Several engage the current conversation about critical editions of ancient Hebrew texts prompted by The Hebrew Bible: A Critical Edition, asking whether such critical texts should be created, and if so, how the evidence should be treated. Some draw on other fields-most notably, ancient Near Eastern studies and cognitive psychology-to illuminate our discipline.

In addition to the overarching context of the Scrolls, what these studies

* We thank the John Fell OUP Research Fund for funding the "Horizons in Textual Criticism" colloquium, and the Oxford Centre for Hebrew and Jewish Studies and its staff for hosting the event.

${ }^{1}$ Three additional papers were presented: Anna Busa, "Rethinking Methodological Approaches: The Phylactery Corpus from the Judean Desert as a Test Case"; Noam Mizrahi, "Variant Readings in the Scriptural Dead Sea Scrolls: A Digital Database Project"; and Molly Zahn, "Genre Theory as a Means of Understanding Scribal Rewriting in Second Temple Judaism." 
hold in common is that they take new approaches to answering old questions. Justus Ghormley, considering ancient Near Eastern evidence and building on Eugene Ulrich's work, carefully articulates a robust typology of textual revision that he applies to Jeremiah. Jean-Sébastien Rey and Matthieu Richelle address the issue of pluriformity and its representation in an edition. Rey utilizes a text with a unique range of evidence-Hebrew Ben Sira-to argue for the inadequacy of eclectic editions. Richelle takes a contrary view, arguing for the feasibility of eclectic editions by demonstrating how a particularly difficult passage can be presented in such an edition. John Screnock, drawing on Emanuel Tov's work on the use of the Septuagint in HB textual criticism, re-orients the issue around the observation that isomorphic OG translation overlaps considerably with transmission in Hebrew. Finally, Jonathan Vroom looks to cognitive psychology for insights into the inner workings and mechanisms of the copyist's brain, in order to address the interplay of orality, memory, visuality, and written text in the copying of texts.

Fresh approaches to old questions are important in any field, and such work remains, rightfully so, at the front edge of text-critical research. However, we wonder whether there is more on the horizon for textual criticism. In particular, are there new questions we can ask and new issues that text-critical data can speak to? Might Hebrew Bible textual criticism become something more than what it currently is? Some recent scholarship explores such possibilities, whether wittingly or not, by drawing on text-critical data as evidence for the study of composition history, ${ }^{2}$ legal interpretation, ${ }^{3}$ theology in the Second Temple period; ${ }^{4}$ other studies redirect textual criticism to focus on the developing text's impact on reading communities ${ }^{5}$ and material philology. ${ }^{6}$ To be sure, scholars have used

2 E.g., Reinhard Müller, Juha Pakkala, and Bas ter Haar Romeny, Evidence of Editing: Growth and Change of Texts in the Hebrew Bible (Atlanta: SBL Press, 2014).

${ }^{3}$ E.g., David Andrew Teeter, Scribal Laws: Exegetical Variation in the Textual Transmission of Biblical Law in the Late Second Temple Period (Tübingen: Mohr Siebeck, 2014).

${ }^{4}$ E.g., Magnar Kartveit, The Origin of the Samaritans, VTSup 128 (Leiden: Brill, 2009), 259312.

${ }^{5}$ E.g., Ronald L. Troxel, "What is the 'Text' in Textual Criticism?," VT 66 (2016): 603-26; "Writing Commentary on the Life of a Text," VT 67 (2017): 105-28.

${ }^{6}$ Liv Lied and Hugo Lundhaug, eds., Snapshots of Evolving Traditions: Jewish and Christian Manuscript Culture, Textual Fluidity, and New Philology, TUGAL 175 (Berlin: De Gruyter, 2017). 
text-critical data for centuries as evidence speaking to a wide range of issues. The question is whether textual criticism as a field, at this point in the history of scholarship, might direct significant amounts of attention to matters other than the reconstruction of earlier textual states.

Here we present but one further possibility. Oscar Wilde famously argued for significant overlap between the critic-whether of art or literature-and the creator of such art or literature; ${ }^{7}$ perhaps we should explore such an approach to textual criticism. ${ }^{8}$ It is commonly acknowledged that, in order to be a good text-critic, one must be a good literary critic (besides a good many other things). ${ }^{9}$ What is to stop the literary/text-critic from applying her literary criticism to text-critical data? Furthermore, critical editions exist in other fields where the aim is not the earliest form of the text, but the best representation of the literary work. ${ }^{10}$ Wilde's observation, that good criticism consists largely in creative artistry, suggests to us that the text-critical endeavor could be an extensively creative endeavor, involving the text-critic's literary sensitivities. Though a critical edition of Hebrew Bible texts aimed at presenting the best, rather than earliest, version of the text would be misguided, greater integration of these two disciplines is possible, in scholars and scholarship that move freely between literary and textual criticism.

The future possibilities for textual criticism are, in our opinion, extensive. The field is alive and well. We hope that the five articles of this section and our introduction will help spur textual criticism on to greater precision and the exploration of wider vistas.

7 Oscar Wilde, "The Critic as Artist," in Intentions (New York: Brentano's, 1905).

${ }^{8} \mathrm{Cf}$. Hindy Najman, who speaks of textual variants "as signs of life-as manifestations of the vitality of the traditions that we are studying," therefore making secondary readings worthy of study in their own right; "Ethical Reading: The Transformation of the Text and the Self," JTS 68 (2017): 517.

${ }^{9}$ Cf. Emanuel Tov, "Criteria for Evaluating Textual Readings: The Limitations of Textual Rules," HTR 75 (1982): 446.

${ }^{10} \mathrm{Cf} .$, e.g., Stanley Wells et al., eds., The Oxford Shakespeare: The Complete Works, $2 \mathrm{~d}$ ed. (Oxford: Oxford University Press, 2005), xxxviii-xxxix. 